\title{
Program Edukasi “TOLUNI" (Tanaman Obat Keluarga Usia Dini) di SDN 015 Kota Samarinda
}

\author{
1*Tri Budi Julianti, ${ }^{1}$ Sylvan Septian Ressandy \\ ${ }^{1}$ Farmasi, Universitas Muhammadiyah Kalimantan Timur \\ *Penulis korespondensi, email: tbj470@umkt.ac.id
}

(Received: 28 June 2020/Accepted: 6 July 2020/Published: 7 July 2020)

\begin{abstract}
Abstrak
TOGA tanaman herbal yang memiliki khasiat sebagai obat yang banyak sekali memiliki manfaat bagi kehidupan, termasuk untuk mengatasi masalah kesehatan secara tradisional. Manfaat TOGA tidak hanya dirasakan oleh kalangan dewasa, tetapi dapat berguna bagi anak-anak. Dewasa ini, sebagian besar anak-anak tidak mengetahui jenis-jenis tanaman obat. Oleh karena itu, pengenalan akan TOGA pada usia dini sangat diperlukan untuk menumbuhkan kecintaan dan minat anak-anak akan tanaman obat yang berkhasiat bagi kesehatan. Dari Program Edukasi "TOLUNI" (Tanaman Obat Keluarga Usia Dini) ini menjadi salah satu wahana pembelajaran yang tepat untuk memperkenalkan berbagai macam mengenai TOGA kepada siswa/i sekolah dasar. Dari program edukasi TOLUNI inipula dapat mendorong sekolah-sekolah yang minim pekarangan agar tetap dapat memiliki banyak tanaman kaya khasiat, sehingga dapat dijadikan wahana pembelajaran bagi para siswa. Program Edukasi "TOLUNI" dilaksanakan di Sekolah Dasar Negeri 015 Kota Samarinda. Sosialisasi edukasi TOGA disampaikan kepada siswa kelas 5 dengan rentang usia 10 - 11 tahun dengan diberikan materi mengenai jenis-jenis TOGA, kemudian para siswa diajak untuk menghias wadah TOGA serta menanam TOGA yang diberi pupuk kompos. Para siswa diajarkan membuat produk tradisional rumahan yaitu jamu sederhana. Selanjutnya dilakukan pembinaan dan pengawasan setelah dilakukan sosialisasi. Dari 15 tanaman TOGA, diperoleh hasil 8 TOGA yang bertahan tumbuh dengan baik.
\end{abstract}

Kata Kunci: TOGA, Usia Dini, Edukasi

\begin{abstract}
TOGA has properties as a drug that has many benefits, including to overcome health problems traditionally. The benefits of TOGA are not only felt by an adult but can be useful for children. Today, most children do not know the types of medicinal plants. Therefore, the introduction of TOGA at an early age is needed to foster children's love and interest in medicinal plants that are beneficial to health. From the "TOLUNI" Education Program (Early Age Family Medicinal Herbs), this has become one of the appropriate learning vehicles to introduce various kinds of TOGA to elementary school students. From this TOLUNI education program can also encourage schools with a minimal yard so that they can still have many rich plants that are useful. "TOLUNI" Education Program is held at 015 State Elementary School in Samarinda City. TOGA education socialization was delivered to grade 5 students with a range of 10-11 years of age with the material given about the types of TOGA, decorate a TOGA container and plant a TOGA that was given compost, make traditional jamu products. Furthermore, guidance and supervision was obtained from 15 TOGA, produce 8 TOGA results that survive well.
\end{abstract}

Keywords: TOGA, Early Age, Education 


\section{Pendahuluan}

Usia dini adalah usia emas ( golden age), dimana perkembangan dalam berfikir, pembentukan karakter dan kepribadian anak khususnya bertingkah laku kedewasaan sedang berlangsung secara progresif dan berkesinambungan. Pertumbuhan sampai perkembangan kehidupan manusia terjadi pada awal periode anak, sehingga pendidikan karakter harus terbentuk pada usia tersebut. Pendidikan karakter pada anak diantaranya belajar menguasai tingkat yang lebih tinggi dari aspek gerakan, berpikir, berperasaan, dan berinteraksi pada sesamanya maupun dengan benda-benda dalam lingkungan sekitar kehidupannya. Strategi pembelajaran yang diberikan pada anak khususnya usia dini bisa didapatkan baik secara pendidikan formal ataupun nonformal. Materi pendidikan formal akan didapatkan dibangku sekolah dengan mata pelajaran yang sudah ditetapkan oleh kementrian pendidikan, sedangkan pendidikan nonformal mereka peroleh dari lingkungan sekitar.

Peranan sekolah untuk membentuk lingkungan sekolah menjadi asri adalah salah satu metode pembelajaran yang dapat diberikan khususnya pengenalan terhadap tanaman. Pemanfaatan tanaman yang ada disekitar lingkungan sekolah dapat dijadikan wahana pembelajaran yang dapat dikembangkan terus menerus. Tetapi melihat semakin kecilnya pekarangan di sekolah bahkan sekolah-sekolah yang berada pada daerah perkotaan sebagian besar tidak memiliki lahan pekarangan sehingga pemanfaatan tanaman sudah sangat jarang dilakukan. Berdasarkan survei yang di lakukan peneliti SDN 015 merupakan salah satu sekolah yang berada pada daerah pinggiran kota, dimana sekolah tersebut tidak memiliki pekarangan khusus karena sekolah berada di pinggir jalan dan di tengah-tengah pemukiman warga.

Tanaman Obat Keluarga (TOGA) merupakan salah satu tanaman yang bisa dijadikan wahana pembelajaran anak untuk lebih mengenal berbagai macam tanaman obat (Bangun, 2012). Metode pemanfaatan tanaman inipun dapat dilakukan dengan beberapa cara, yaitu menanam di dalam pot kaleng bekas atau dalam polybag tanaman yang dimasukkan dalam wadah plastik dan bisa digantung pada sekitar lingkungan sekolah. Menurut Harniawati, D, dkk (2017) pada artikel Diana, dkk 2015 menyatakan edukasi TOGA merupakan pembelajaran edukatif yang dapat dijadikan wahana dalam pembentukan karakter dan prinsip kemandirian dalam upaya pengobatan keluarga. Tanaman Obat Keluarga (TOGA) ini sendiri merupakan tanaman hasil budidaya rumahan yang berkhasiat sebagai obat (Aisyah, dkk, 2010).

Program Edukasi "TOLUNI" ialah program edukasi pembelajaran Tanaman Obat Keluarga pada Usia Dini. Program pembelajaran ini ialah terobosan baru mengenai pengenalan tanaman obat kepada anak-anak usia dini secara langsung bertujuan meningkatkan upaya pengobatan mandiri pada masyarakat dan usia dini. Penerapan pengenalan TOLUNI dapat dikembangkan dari anak sekolah dasar yang menjadi metode pembelajaran di sekolah. Pelatihan pembelajaran edukatif tentang pemanfaatan tanaman obat dimulai dari memberikan pemaparan mengenai penjelasan TOGA, pengenalan jenis-jenis TOGA, teknik pembuatan media tanam, teknik penanaman TOGA, Teknik pembuatan pupuk organik, pembelajaran tentang manfaat dari TOGA yang ditanam, penghiasan wadah serta pembuatan produk obat tradisional rumahan. Dengan adanya program tersebut maka setiap anak bahkan warga sekitar sekolah dapat peduli dengan kesehatan dan dapat memanfaatkan TOGA tersebut secara mandiri sehingga dapat meningkatkan upaya pengobatan mandiri. 


\section{Metode}

\subsection{Strategi}

Strategi Kegiatan untuk Program Edukasi "TOLUNI" (Tanaman Obat Keluarga Usia Dini) di SDN 015 ini, antara lain:

a. Sosialisasi dengan pemberian materi tentang pengenalan TOGA, jenis-jenis TOGA dan pemanfaatan TOGA untuk berbagai macam penyakit

b. Anak-anak sebelumnya diajak untuk menghias wadah TOGA dengan gambar-gambar yang disukai anak-anak yang selanjutnya dilakukan penanaman TOGA pada wadah tersebut. Kemudian dilakukan pemberian pupuk organik dan diletakkan pada sekitar sekolah

c. Program TOLUNI juga melakukan praktek pembuatan produk sediaan obat tradisional rumahan yang kelak bisa di praktekkan di rumah untuk peningkatan upaya pengobatan secara mandiri

\subsection{Rencana Kegiatan}

a. Sosialisasi edukatif TOGA disampaikan di ruang kelas kepada siswa kelas 5, materi yang diberikan tentang mengenal tanaman obat, mengenal lebih dekat beberapa jenis tanaman obat. Para siswa ditunjukkan tanaman obat yang dibawa sehingga dapat melihat langsung.

b. Menghias wadah yang akan digunakan untuk menanam TOGA menggunakan cat warna yang sudah disiapkan guna menumbuhkan ketertarikan siswa terhadap tanaman obat. Metode ini juga dapat menarik minat siswa untuk lebih peduli dengan tanaman yang ditanam.

c. Para siswa di ajak untuk ikut serta dalam melihat pupuk kompos organik dan teknik-teknik penanaman TOGA ke dalam wadah-wadah yang sudah dihias dengan menjelaskan khasiat dan manfaat dari tanaman-tanaman obat yang ditanam.

d. Para siswa dan guru SDN 015 diajarkan cara pengolahan tanaman obat agar dapat menghasilkan produk tradisional rumahan.

e. Dari hasil penanaman TOGA yang dilakukan para siswa, dilakukan pembinaan dan pengawasan. Pembinaan yang dilakukan melibatkan para siswa secara langsung dalam proses kegiatan perawatan seperti menyiram tanaman, pemberian pupuk organik dan membersihkan kotoran yang terdapat di sekitar tanaman setiap pulang sekolah. Sedangkan tahap pengawasan dilakukan setiap 2 minggu pada bulan pertama pada masing-masing tanaman para siswa, selanjutnya para siswa diminta untuk dapat merawat dengan rutin agak tanaman tersebut bisa terjaga dengan baik.

\section{Hasil dan Pembahasan}

Kegiatan Edukasi TOLUNI (Tanaman Obat Keluarga Usia Dini) ini dilaksanakan pada Sekolah Dasar Negeri 015 tepatnya di jalan Anggur kelurahan Sidodadi Samarinda. Tema pengabdian masyarakat ini diambil berdasarkan hasil survey yang terlebih dahulu dilakukan dengan melakukan metode wawancara terhadap sebagian anak-anak tingkat sekolah dasar tentang tingkat pengetahuan mengenai tanaman obat yang ada disekitar rumah mereka. Dari wawancara tersebut dilihat bahwa sebagian anak tidak mengetahui jenis-jenis tanaman obat dan rendahnya tingkat kegemaran anak terhadap jamu yaitu hasil dari pembuatan tanaman obat.

Berdasarkan survey tersebut maka dilakukanlah pengabdian masyarakat dengan memberikan edukasi mengenai tanaman obat pada usia dini khususnya untuk siswa-siswa sekolah dasar. Siswa yang diberikan edukasi kisaran umur 10 - 11 tahun yang duduk di kelas lima. Edukasi yang diberikan berupa pemberian informasi mengenai jenis-jenis TOGA, kandungan TOGA, manfaat TOGA, cara pembuatan dan cara pemakaiannya. Selanjutnya para siswa diajak untuk menanam TOGA dengan benar, sebelumnya wadah yang akan digunakan diwarnai agar terlihat lebih 
menarik bagi anak-anak. Penanaman TOGA bertujuan untuk menyiapkan tanaman yang dapat berguna sebagai obat, untuk swamedikasi serta dapat digunakan untuk keperluan sakit secara mendadak sehingga dapat dijadikan sebagai pertolongan pertama sebelum datang untuk berobat ke dokter (Sari, D dkk, 2015, Febriana, 2012). Anak-anak pula diedukasi dalam pentingnya melakukan pemeliharaan secara rutin guna pertumbuhan TOGA yang mereka tanam dapat tumbuh subur sehingga dapat mereka gunakan bagi kehidupan mereka. TOGA tersebut juga bisa dijadikan usaha yang kelak dapat diperbanyak secara mandiri sehingga menjadi tambahan penghasilan bagi keluarga mereka.
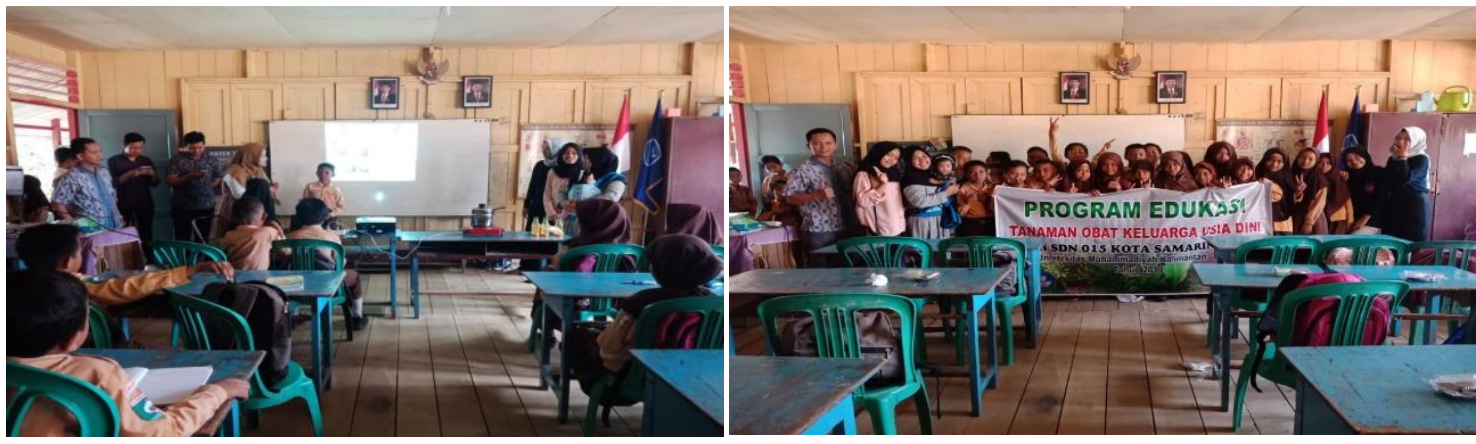

Gambar 1. Pemberian Edukasi TOLUNI oleh Mahasiswa

Setelah itu para siswa diajak untuk sama-sama mempraktekkan cara pembuatan jamu sehat. Jamu yang dibuat yaitu jamu temulawak yang dicampurkan dengan bahan tambahan seperti pemanis dan perasa sehingga digemari oleh anak-anak. Usia 10-11 tahun merupakan usia emas perkembangan dimana pertumbuhan dan perkembangan anak masih harus dipantau. Oleh karena itu sebagai orang tua kita wajib dalam mengoptimalkan pertumbuhan, perkembangan dan meningkatkan daya tahan tubuh anak antara lain asupan gizi, perilaku, pendidikan dan perlindungan kesehatan dengan baik (Yulianto, dkk, 2016). Temulawak merupakan salah satu TOGA yang mudah tumbuh bila ditanam dengan baik. Temulawak banyak digunakan sebagai bahan baku obat tradisional karena memiliki banyak khasiat diantaranya memiliki kandungan antioksidan yang dapat menghambat radikal bebas yang berguna sebagai pertahanan tubuh terhadap pengaruh buruk yang disebabkan oleh radikal bebas. Khasiat temulawak pula dapat berfungsi sebagai upaya pemeliharaan kesehatan dan pengobatan penyakit (Rosidi, dkk, 2004, Agoes, 2010). Hasil pembuatan jamu ini langsung diberikan kepada para siswa, karena semua bahan dan alat yang digunakan dalam pembuatan jamu telah melalui uji coba sebelumnya di laboratorium UMKT. Hampir 80\% siswa sangat suka dengan hasil jamu yang telah mereka buat.

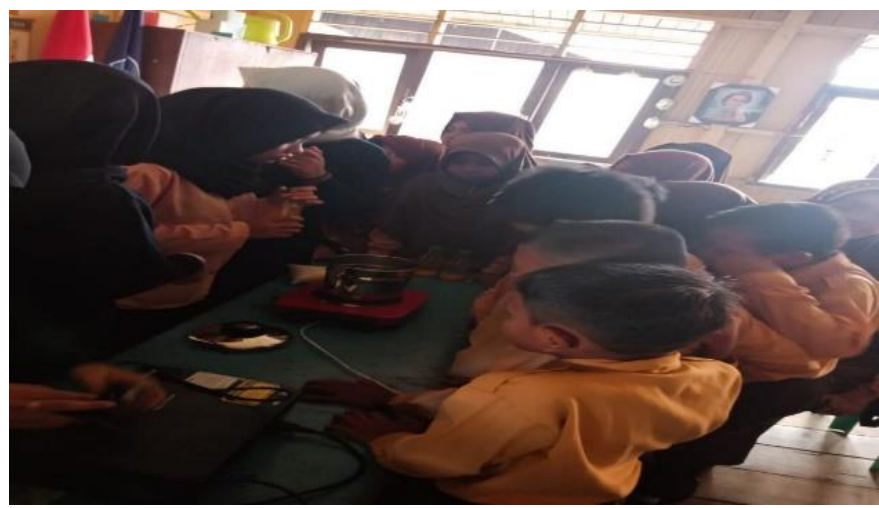

Gambar 2. Praktek Pembuatan Sediaan Jamu Sehat Kepada Siswa 


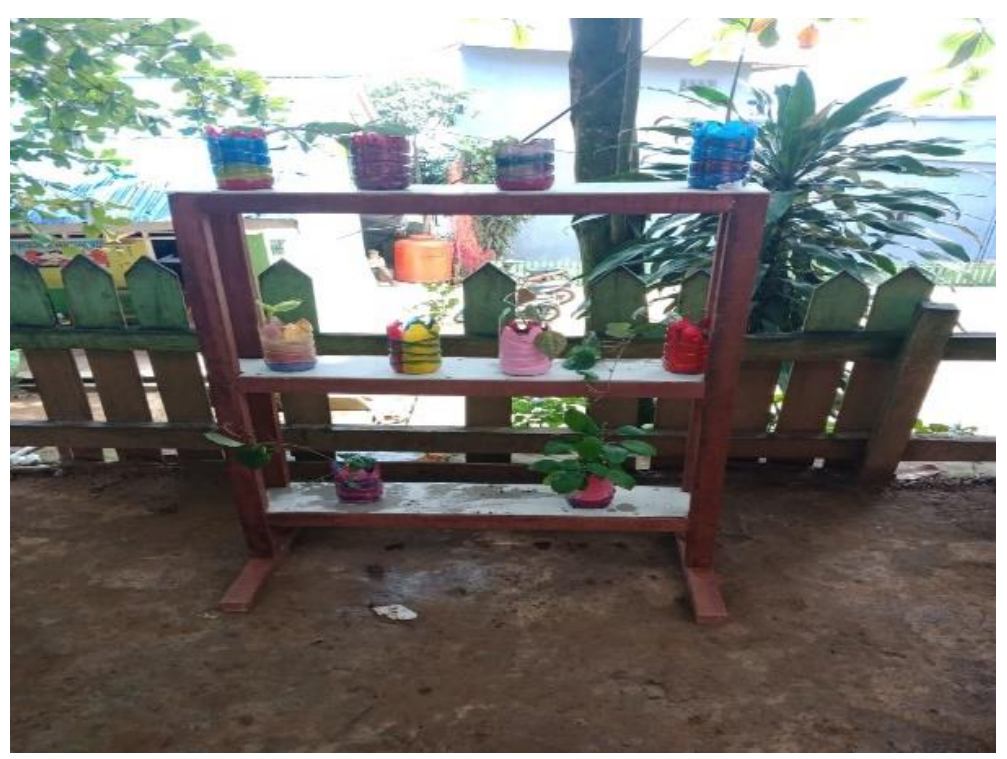

Gambar 3. Hasil Penanaman TOLUNI Oleh Siswa

Selanjutnya siswa-siswa SDN 015 Samarinda diberikan pemahaman bahwa jamu berasal dari TOGA yang mereka tanam dan meyakinkan bahwa sebagian besar TOGA merupakan tanaman obat yang dapat diolah dengan mudah, salah satunya dapat dijadikan sebagai jamu rumahan yang tidak berasa pahit, memiliki niali etetika yang baik serta enak untuk dikonsumsi. Selain itu sayuran serta bumbu dapur juga merupakan tanaman alami yang memiliki potensi sebagai obat dan masuk dalam kategori TOGA (Rifki F, 2018). Dari pengabdian ini diharapkan para siswa dapat berbagi edukasi kepada masyarakat sekitar termasuk keluarga mereka mengenai macam-macam manfaat TOGA sehingga dapat meningkatkan motivasi masyarakat untuk memperbanyak bertanam TOGA di lingkungan sekitar mereka. Dari tanaman TOGA pula diharapkan dapat menjadi pondasi usaha pangan secara mandiri dan dapat meningkatkan taraf ekonomi dan kesehatan masyarakat sekitar SDN 015.

\section{Kesimpulan}

Kegiatan pengabdian kepada masyarakat berjalan dengan baik dan memiliki manfaat bagi para siswa SDN 015 Samarinda dalam hal edukasi TOLUNI (Tanaman Obat Keluarga Usia Dini). Selain itu, penting untuk mengajak anak-anak untuk menjaga kesehatan dengan rajin dalam mengkonsumsi jamu sehat agar daya tahan tubuh anak terjaga.

\section{Persantunan}

Segala puji dan syukur kami panjatkan ke hadirat Allah SWT yang telah memberikan kesempatan kepada kami Dosen Universitas Muhammadiyah Kalimantan Timur untuk melaksanakan pengabdian kepada masyarakat sebagai salah satu bentuk kegiatan Tridharma Perguruan Tinggi. Kegiatan pengabdian ini dapat terlaksana berkat dukungan dari berbagai pihak. Oleh karena itu dalam kesempatan ini perkenankanlah kami menyampaikan terima kasih kepada: 1. Rektor Universitas Muhammadiyah Kalimantan Timur

2. Dekan Fakultas Ilmu Kesehatan dan Farmasi Universitas Muhammadiyah Kalimantan Timur

3. Pimpinan Lembaga Pendidikan dan Pengabdian Kepada Masyarakat (LPPM) Universitas Muhammadiyah Kalimantan Timur

4. Ketua Program Studi Farmasi Universitas Muhammadiyah Kalimantan Timur

5. Kepala sekolah, Para Guru serta Siswa/i SDN 015 Kelurahan Sidodadi Samarinda 
6. Para mahasiswa dan berbagai pihak yang tidak dapat kami sebutkan satu persatu yang telah membantu terlaksananya kegiatan LPPM ini.

Kegiatan pengabdian masyarakat ini masih belum mencapai target ideal karena keterbatasan waktu dan dana yang tersedia. Untuk mencapai tujuan yang diinginkan, menurut kami perlu kiranya dilakukan kegiatan pengabdian masyarakat di lain waktu sebagai kelanjutan kegiatan tersebut. Namun demikian, besar harapan kami semoga pengabdian kepada masyarakat ini dapat memberikan manfaat. Amien.

\section{Referensi}

Agoes A. (2010). Tanaman Obat Indonesia. Jakarta: Selemba Medik.

Aisyah.D, Laksmi. L.I, Husnaa, U. (2010). Potensi Tumbuhan Indonesia Sebagai Bahan Obat Tradisional Dengan Pendekatan Teknik Pengolahan Traditional Chinese Medicine (TCM). Malang: Universitas Negeri Malang.

Bangun, A. (2012). Ensiklopedia Tanaman Obat Indonesia. Bandung : Indonesia Publishing House.

Diana Sari, Ida, Yuyun Yuniar, Selma Siahaan, and Muhamad Syaripuddin. (2015). "Tradisi Masyarakat Dalam Penanaman Dan Pemanfaatan Tumbuhan Obat Lekat Di Pekarangan Community Tradition in Planting and Using Medicinal Plant in Surround Home Yard." Jurnal Kefarmasian Indonesia 5 (2):12332.http://download.portalgaruda.org/article.php?article=378944\&val=4889\&title=Tradisi Masyarakat dalam Penanaman dan Pemanfaatan Tumbuhan Obat Lekat di Pekarangan.

Febriana. (2012). Pengembangan Sirih Merah (Piper crocatum) Sebagai Herbal Terstandar untuk Mengatasi Keputihan Terhadap Trichomonas vaginalis. Artikel ilimiah. Bandung: Universitas Padjajaran.

Febriansah, Rifki. (2018). "Pemberdayaan Kelompok Tanaman Obat Keluarga Menuju Keluarga Sehat Di Desa Sumberadi, Mlati, Sleman." BERDIKARI : Jurnal Inovasi Dan Penerapan Ipteks 5 (2): 80-90. https://doi.org/10.18196/bdr.5221.

Rosidi, Ali, Ali Khomsan, Budi Setiawan, and Dodik Briawan. (2004). "Potensi Temulawak (c," no. 1995.

Yulianto, Susilo, and Ag. Kirwanto. (2016). "Pemanfaatan Tanaman Obat Keluarga Oleh Orang Tua Untuk Kesehatan Aak Di Duwet Ngawen Klaten."Jurnal Terpadu Ilmu Keperawatan 5 (1): 75-80. 